\title{
A PROPOSAL OF SIMULATION MODEL OF A WIND-STEERING SYSTEM FOR SAILING YACHTS, BASED ON SINGLE-STAGE SERVO- PENDULUM COUPLED WITH MAIN RUDDER
}

\author{
Andrzej Piętak, Assoc. Prof. \\ Maciej Mikulski, Ph.D. \\ Marek Melzacki, M. Sc. \\ Kamil Czerwiński, B. Sc. \\ University of Warmia and Mazuria in Olsztyn, Poland
}

\begin{abstract}
The aim of this study was to investigate possible application of fast design prototyping methods for wind-steering systems used in offshore sailing yachts. The development of such methods would help to speed up the construction work and reduce the scope of necessary experimental research, prior to implementation of the system. In the present work, based on an analysis of existing designs of windvane systems, a preliminary selection of the system configuration has been undertaken, in terms of a compromise between efficiency, performance, and design complexity. Construction design of a single-stage, servo - pendulum system, has been developed by using the Autodesk Inventor design package. Next, based on the design data, a simulation model of the system, has been produced by using Matlab - Simulink software and SimMechanics library. The model was further verified in terms of kinematics mapping with the use of Matlab visualization tools.
\end{abstract}

Keywords: sailing yachts, wind-steering system, automation

\section{Introduction}

Issue of automation of steering has reached greater and greater importance both for road, water and air craft. In the simplest application the problem consists in keeping a constant course respective to a given coordinate system (usually with respect to geographical north ). For deep-sea sailing ships (tall sail ships, sailing yachts) it is of a high importance to keep a constant course against direction of wind which, at a given position of sails, ensures propelling force to the ship. Wind - steering system is a device (in contrast to an electric giropilot) whose aim is to keep a constant course against wind. Windvane is set at a requested angle against an apparent wind direction. Motion of the windvane, when it departs from wind direction line, is transferred, through couplings, cords and hinges, to the main or auxiliary rudder or a balance tab which consequently corrects course of the yacht.

The concept of self-steering appeared as early as in the end of 15 th century. However one of the first practical and welldocumented applications of a self steering gear was the system installed by Martin-Marine on the yacht „Arielle” in 1936 [5]. This very simple system was not free of many drawbacks. In order to obtain a sufficienty large force on windvane for putting the rudder into motion it was necessary to apply a large surface area of the windvane itself. The application of a vane with large surface area, in view of its large inertia, generated a large phase error in performance of the yacht steering gear. The features of the system limited its range of application.

The need of achieving a better precision of steering in a possibly broad range of weather conditions was forcing a natural evolution of self-steering systems. There are today a few specialty firms devoted to manufacturing and developing such devices $[12,13,14]$. The development of the systems comes mainly from experience gained by their producers. Results of reliable research work, both experimental and theoretical, on effectiveness of such systems are still lacking. A few attempts to a systematic description of self-steering gear - yacht systems were undertaken by Dąbrowski and Skórski $[2,3,4]$. The authors proposed a mathematical model of the self-steering gear - yacht system, solved in Matlab-Simulink environment. The model was verified by using data obtained from real-object tests. The concept proposed by Skórski was developed in an interesting way into research on possible application of active regulation of windvane jamming angle in order to improve properties of the system [6]. 
Progress in the field of the modelling of multi-mass systems has brought novel simulation tools. However there is still a need of conducting further research on self-steering systems for sailing yachts by implementing a modern approach to forming mathematical models. In this work SimMechanics software has been applied to create a simulation model of complex kinematic joints of a self-steering system based on a single-stage servo-pendulum coupled with main rudder of the yacht.

\section{Analysis of design solutions of wind-steering systems}

The concept of wind-steering system has underwent a gradual evolution. A comprehensive description of implemented solutions can be found in the publication of Forthaman [5]. The systems both with auxiliary rudder (Fig.1.b; Fig.1.c) or direct coupling of the vane and main rudder (Fig.1.a) were considered. In case of the direct coupling, forces exerted on the vane were to overcome bearing friction forces, hydrodynamic force, drag resulting from motion transferring and those generated on rudder blade surface. The crucial issue of this design was too low force generated on windvane at light breeze. At a greater wind force yacht developes a greater speed, that results in a significant rise of hydrodynamic forces, hence an optional solution for such device would be to increase area of vane surface. However this becomes impractical and generates a large phase error [8].

For proper work of a wind-steering system, value of the force generated on its vane, which is a function of apparent wind speed and vane surface area, should be increased. Such effect can be reached by making use of water flow around moving hull as well as of interaction between intermediate mechanisms and an executive element. A helpful device may be e.g. a trimmer or servo-pendulum. In a hybrid design (with a servo-pendulum and additional trimmer, Fig.1.b) a crucial innovation was the introduction of an intermediate hydrodynamic device to support the work of the windvane interacting with the rudder. Trimmers had to change geometry of a body immersed in water flow around it, and as a result to change the generated hydrodynamic force and consequently to swing the servo-pendulum. In this case it was decisive to maintain an appropriate proportion between surface area of trimmer and that of pendulum blade. The solution has significantly increased sensitivity of the device but greatly complicated its construction itself.

Application of the windvane of horizontal rotational axis (Fig.1.c) made it possible to obtain a high amplitude of excitation even at slight departing from a given course by the yacht. It positively affected sensitivity and rate of reaction of the control system. The problem of achieving a sufficiently large force for rudder blade rotation was solved by separating the steering signal, i.e. windvane inclination, from the signal which excites steering moment.

The performed review of available design solutions has lead to selection, for further analysis, of a system with vertical windvane interacting with a single servo-pendulum responsible for hydrodynamic amplification of wind steering signal. In the opinion of these authors the solution is an optimum compromise between effectiveness, operational accuracy and design complexity of the system.
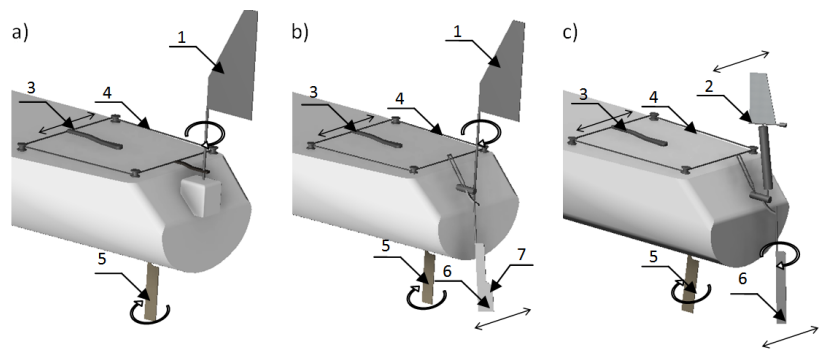

Fig. 1. Design solutions of wind-steering systems

a) a device of a direct impact of windvane onto main rudder; b) a device with servo-pendulum and auxiliary trimmer;

c) a servo-pendulum device with horizontal rotation axis of windvane; 1 windvane with vertical rotation axis; 2 - windvane with horizontal rotation axis; 3 - steering gear (tiller); 4 - system of pulley blocks and cables; 5 - main rudder blade; 6 - servo-pendulum blade; 7 - trimmer installed on pendulum blade;

\section{Design of wind-steering system with single- stage servo-pendulum}

During initial work a conceptual design of wind-steering system was prepared by using Autodesk Inventor software [7]. Fig. 2 shows images of principal elements of the system in question. A schematic kinematic diagram of the whole wind-steering system and main rudder gear of a yacht is presented in Fig. 3

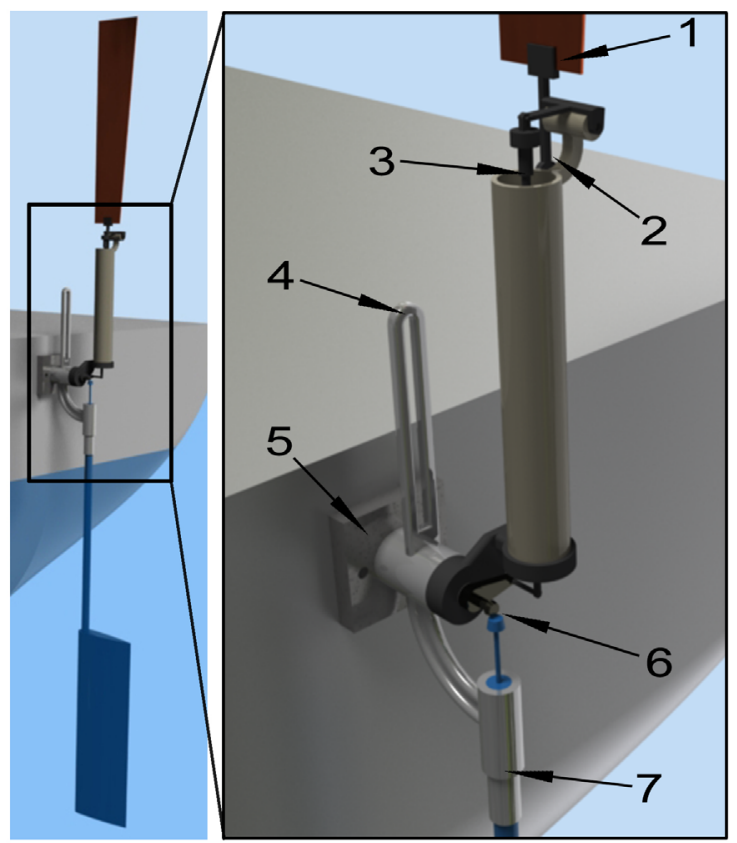

Fig. 2. Elements of construction of a wind-steering system, visualized by means of Autodesk Inventor software. 1-windvane; 2 - counterweight; 3 - push rod; 4 - pendulum arm, 5 - footing of winds-steering system (fixed upon yacht's transom); 6 - bevel gear; 7 - pendulum post 
During sailing at a given course, the windvane is set according to apparent wind direction line. The counterweight keeps the windvane vertically. Similarly, the pendulum blade is so set as to make hydrodynamic force as low as possible. The system maintains equilibrium as long as the yacht does not start departing from a given course (under assumption that wind direction is unchanged). In such situation the windvane, under action of wind force applied to its surface, departs from its equilibrium position, that makes the system operating. Inclination of the windvane is transferred through the push rod to the toothed wheel of the bevel gear placed on the main post of the wind-steering system, stimulating this way rotation of the pendulum blade and changing its angle of attack.

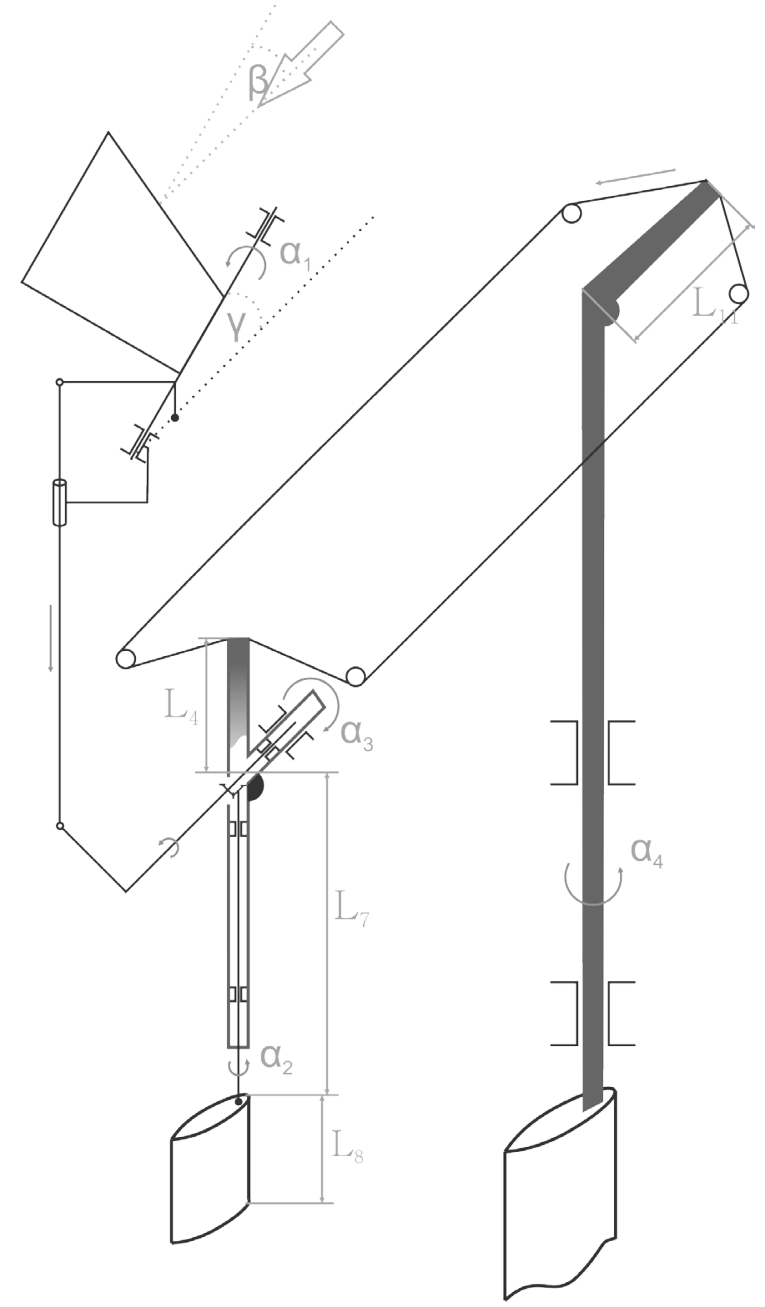

Fig. 3. Schematic diagram of kinematics of the wind - steering device - main rudder system.

$\beta$ - angle of departure from course, $\gamma$ - windvane jamming angle; $\alpha_{1} \div \alpha_{4}$ - inclination angle of: windvane, pendulum blade, pendulum, main rudder, respectively; $L 4, L 7, L 8$, - length of arm, post and pendulum blade, respectively; 11 - length of tiller

The hydrodynamic force generated on blade surface makes the pendulum rotating around a straight line which determines direction of yacht motion. Features of the bevel gear make it possible to incline the pendulum along with the simultaneous decreasing of blade angle of attack, without any interference into position of the windvane, until the next equilibrium state is reached. This way the system aims at self-stabilization, that simultaneously limits maximum inclination of the pendulum and prevents it against sticking off the water. To this end, the pendulum arm (Fig. 2., item 4.) transfers steering moment to the tiller or steering wheel through the system of pulley blocks and cables. Rotation of the main rudder triggers return of the yacht to set course. Consequently, angle of inclination of wind direction from windvane axis decreases, hence aerodynamic force acting on it also decreases. The counterweight of the windvane gives rise to its return to equilibrium position, that generates pendulum blade rotation in the other direction. Shape of water flow round the blade leads to return of the pendulum arm to its initial position.

\section{Mathematical model of the wind-steering system with single-stage servo-pendulum}

Operational effectiveness of the yacht - wind -steering device system considered as an automatic control system is affected by a very large number of factors such as: size and shape of windvane, construction and inertia moment of yacht, apparent wind speed, shape of auxiliary rudder blade, applied gear ratio, as well as friction forces, inclination angle of yacht from set course etc.

In order to analyse effectiveness of such system it is necessary to develop an adequate simulation model which would allow to select optimum parameters of the system in the aspect of possible steering in given sailing conditions. In the so defined problem the yacht- wind-steering device system is consisted of a few dozen of stiff solids (bodies) connected by means of passive mechanical elements. Geometrical and kinematic constraints are assigned to the stiff bodies and the forming of mathematical model in question consists in solving a Lagrange matrix equation for multi-mass system.

Analytical determination of appropriate matrix quantities is very difficult in case of a few dozen of elements. Taking into consideration geometrical complexity of such construction, these authors resigned from direct formulation of system's dynamic equations in favour of using a dedicated, objectorientated simulation environment. Matlab - Simulink software of Mathworks firm together with SimMechanics library [10] was applied. For modelling purposes the yacht wind-steering device system was divided into 92 component elements. Fig. 4 presents the schematic block diagram of wind-steering system model. In the diagram, macro-elements are considered to be separate sub-models. The exemplary schematic diagram of the sub-model of the frame of windsteering system is shown in Fig. 5.

In order to precisely reproduce dynamics of the system the Simulink makes use of parametrization procedure for particular mechanical elements by indicating location of their constraints, centre of gravity, mass and inertia moment tensor at initial instant. Only basic geometrical and material data for all component elements were assumed to be input parameters of the model. 


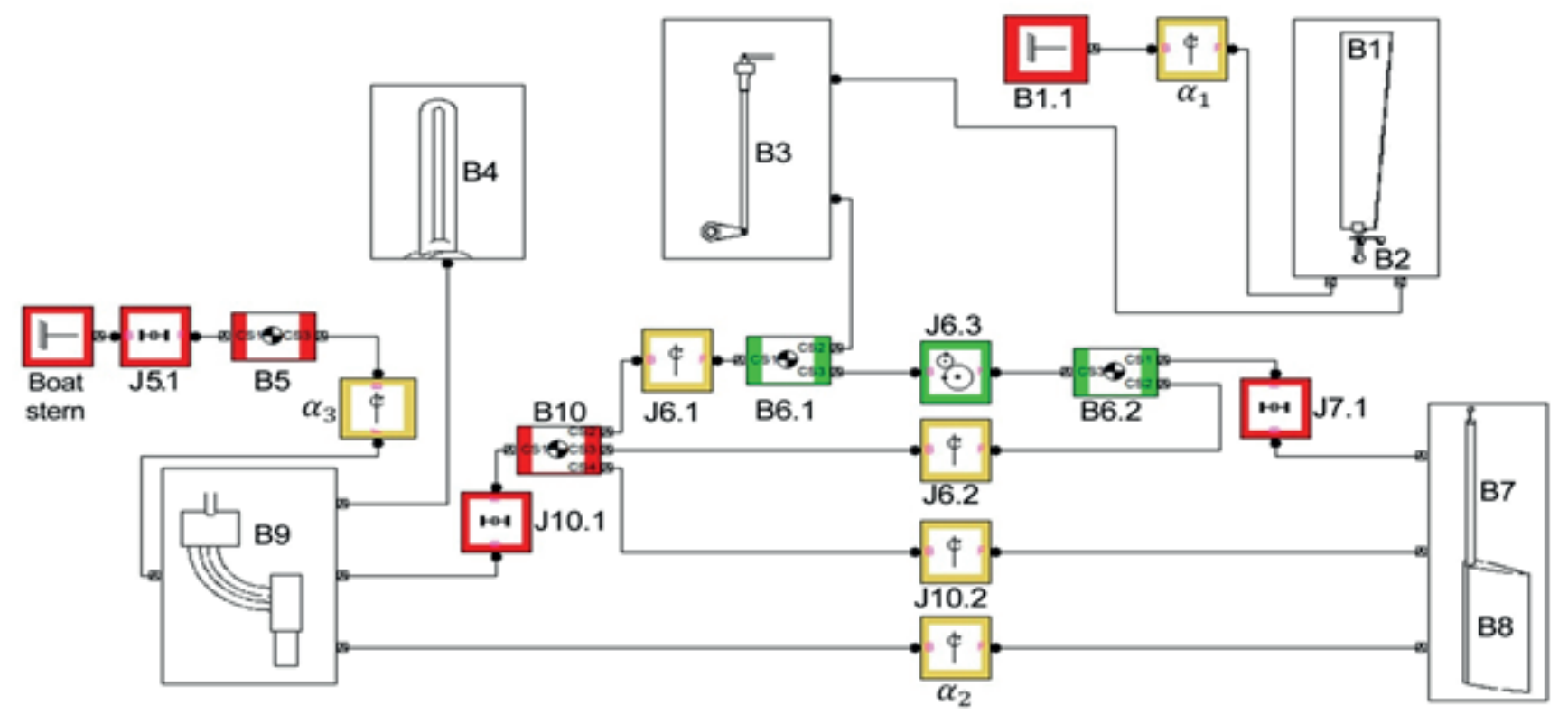

Fig.4. Schematic block diagram of wind-steering system model, prepared in Simulink (SimMechanics) environment. Symbol B represents particular mechanical elements, J-joints (welded, screwed or rotary ones). Numerical indices stand subsequently for a macro-element number (the same notion as in Fig.2) and number of a component element of the macro-element.

Tab. 1. Elements of sub-model of wind-steering system frame (Fig. 5.)

\begin{tabular}{|c|c|c|c|c|}
\hline B 9 & \multicolumn{4}{|c|}{ Wind-steering system frame } \\
\hline \multicolumn{3}{|c|}{ Bodies } & \multicolumn{2}{|r|}{ Joints } \\
\hline Symb. & Type & Description & Symb. & Description \\
\hline В 9.1 & Pipe & $\begin{array}{l}\text { Main axle of } \\
\text { frame }\end{array}$ & \multirow[t]{2}{*}{ J 9.1} & \multirow[t]{2}{*}{ Welded joint } \\
\hline \multirow{2}{*}{ B 9.2} & \multirow{2}{*}{ Cylinder } & \multirow{2}{*}{$\begin{array}{l}\text { Vertical } \\
\text { connection }\end{array}$} & & \\
\hline & & & \multirow{2}{*}{ J 9.2} & \multirow{2}{*}{ Welded joint } \\
\hline \multirow{2}{*}{ В 9.3} & \multirow{2}{*}{ Cylinder } & \multirow{2}{*}{$\begin{array}{l}\text { Horizontal } \\
\text { connection }\end{array}$} & & \\
\hline & & & \multirow[b]{2}{*}{ J 9.3} & \multirow[b]{2}{*}{ Welded joint } \\
\hline B 9.4 & Pipe & $\begin{array}{l}\text { Windvane blade } \\
\text { rotation axle }\end{array}$ & & \\
\hline
\end{tabular}

The input data are sent to the mathematical model. They are taken from technical documentation of the device, generated by Autodesk Inventor software where the design project is under preparation. For modelling purposes was prepared an external sub-model intended for the calculating of element masses and inertia moments along axes of the coordinate system. The coordinate system was assumed yacht-fixed and so orientated as to get $\mathrm{z}$-axis complying with yacht hull symmetry axis and $y$-axis pointing direction of hydrostatic buoyancy force. Under such assumptions all tensors form diagonal matrices. As in initial position all the elements of the wind-steering system are placed along one of three axes of the coordinate system, it can be possible to write the following for $i^{\text {th }}$ elements:

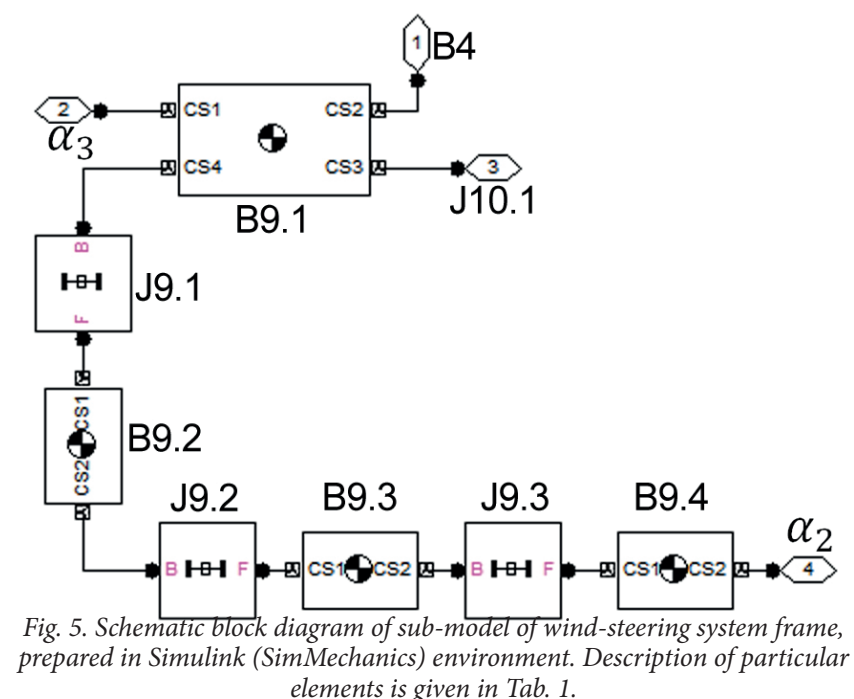

The input data are sent to the mathematical model. They are taken from technical documentation of the device, generated by Autodesk Inventor software where the design project is under preparation. For modelling purposes was prepared an external sub-model intended for the calculating of element masses and inertia moments along axes of the coordinate system. The coordinate system was assumed yacht-fixed and so orientated as to get $\mathrm{z}$-axis complying with yacht hull symmetry axis and y-axis pointing direction of hydrostatic buoyancy force. Under such assumptions all tensors form diagonal matrices. As in initial position all the elements of the wind-steering system are placed along one of three axes of the coordinate system, it can be possible to write the following for $\mathrm{i}^{\text {th }}$ elements: 


$$
\mathrm{M}_{\mathrm{i}}=\left[\begin{array}{ccc}
\mathrm{I}_{\mathrm{x}, \mathrm{i}} & 0 & 0 \\
0 & \mathrm{I}_{\mathrm{y}, \mathrm{i}} & 0 \\
0 & 0 & \mathrm{I}_{\mathrm{z}, \mathrm{i}}
\end{array}\right]
$$

For instance, for the element 3.1, i.e. push rod (rod made of a material of $\rho$ density, radius $-r$, length $-\mathrm{L}$ ):

$$
\left\{\begin{array}{c}
\mathrm{m}_{3}=\pi \rho_{3} \mathrm{~L}_{3} \mathrm{r}_{3}^{2} \\
\mathrm{I}_{\mathrm{y}, 3}=\frac{1}{2} \mathrm{~m}_{3} \mathrm{r}_{3}^{2} \\
\mathrm{I}_{\mathrm{x}, 3}=\mathrm{I}_{\mathrm{z}, 3}=\frac{1}{12}\left(3 \mathrm{r}_{3}^{2}+\mathrm{L}_{3}^{2}\right)
\end{array}\right.
$$

The remaining elements were parametrized in the same way.

According to the design project, the coupling of the wind-steering system with the main rudder was arranged by applying the system of pulley blocks and cables. Position of reverse blocks is determined by position of the end of main rudder tiller at its maximum inclination (90o). In the model in question the coupling was modelled as a massless gear of the ratio determined by the length of main rudder tiller and the length of wind-steering system arm. The simplification is deemed justified in view of a slight mass of the cables in comparison to the remaining mechanical elements. Analysing geometry of the coupling one can show that at a given inclination ( $\alpha 3$ ) of the arm of wind-steering system the main rudder will be rotated by the following angle :

$$
\alpha_{4}=2 \arccos \left[1-\frac{\mathrm{L}_{4}}{\mathrm{~L}_{11}}\left(1-\cos \left(\frac{\alpha_{3}}{2}\right)\right)\right]
$$

where: L11 and L4 are length of main rudder tiller and length of wind-steering system arm, respectively. Symbols used in the formulae $(4) \div(6)$ are highlighted in Fig. 3 .

On the system should be additionally applied geometrical constraints connected with the slope angle of windvane axis, $\gamma$, (the so called vane jamming angle ). In the case of strictly horizontal position of the axis $\left(\gamma=90^{\circ}\right)$ the windvane acts as a binary sensor. Even a slight departure of yacht from its course $(\beta)$ results in the maximum permissible inclination of the windvane. This makes reactions of the control system independent on magnitude of disturbance and may therefore generate switchover events and a lack of stability. On the other hand, in case of $\gamma=0^{\circ}$, a system of vertical windvane rotation axis with its main drawback (consisted in too low amplitude of steering signal), is obtained. The windvane jamming angle controls amplification of steering signal. Basing on an analysis of the system's geometry (Fig. 3) it is easy to show that, at a given value of the angle $\gamma$ and departure of yacht from its course by the angle $\beta$, the windvane rotation angle can be expressed by the following relation:

$$
\alpha_{1}=\operatorname{atan}\left(\frac{\tan \beta}{\sin \gamma}\right)
$$

Analogous geometrical constraints can be also imposed onto the pendulum blade. By making its inclination possible an additional optimizing parameter capable of controlling hydrodynamic amplification of system's reaction, is obtained.

In case of the pendulum blade, to introduce an additional constraint for counteracting against its emersion off the water, is necessary. Construction of the wind-steering system is secured against this phenomenon in a natural way as a result of tending the blade angle of attack to zero during inclination of the pendulum out of its vertical position. Consequently, regardless of applied gear ratio, maximum value of the pendulum inclination amounts exactly as much as value of the inclination angle of the windvane in given conditions. However during selecting the system's geometrical parameters the yacht heel angle $(\varphi)$ should be taken into consideration. Analysis of the system's geometry leads to the relation for length of immersed part of the blade in function of heel angle, windvane inclination angle and pendulum length, as follows:

$$
\Delta \mathrm{L}=\left(\mathrm{L}_{7}+\mathrm{L}_{8}\right) \cos \left(\alpha_{3}+\varphi\right)-\mathrm{L}_{1} \cos (\varphi)
$$

The elements of the system, numbered 1, 8, 11 ( standing for the windvane, pendulum blade, main rudder blade - Fig. 2.) may be loaded with external excitations in the form of aero- and hydrodynamic forces. Analoguosly, in joints of kinematic pairs both dry and viscous friction takes place. Moreover, in case of the pendulum blade to take into account hydrostatic buoyancy forces is necessary. This paper is focused on verification of mathematical kinematic model only. A detail analysis of dynamics of the system will be presented in the next part of the work.

\section{Analysis of operational correctness of kinematic model}

To make it possible to use the model for investigation of dynamic performance of the yacht - wind - steering - device system it is necessary to preliminarly analyse correctness of its operation. The verification contained two stages. In the first stage parametrization correctness of particular mechanical elements in simulation structure, was examined. To this end, Matlab V-R Toolboox, a visualization tool, was applied. By correct introduction of connections of geometrical constraints and values of tensors into considered project, an appropriate mapping of the system's geometry during visualization is reached. In Fig. 6 is presented a fragment of visualization of the mathematical model in which inertia moments of structural elements are taken into account.

Evaluation of conformity of the mathematical model consisted in comparison of elementary motions of windsteering system, which result only from angular excitations in joints. The test on correctness of operation was parallely conducted for the design project prepared with the use of Autodesk Inventor software and the mathematical model implemented within Simulink environment. Exemplary results of the simulation are presented below. 


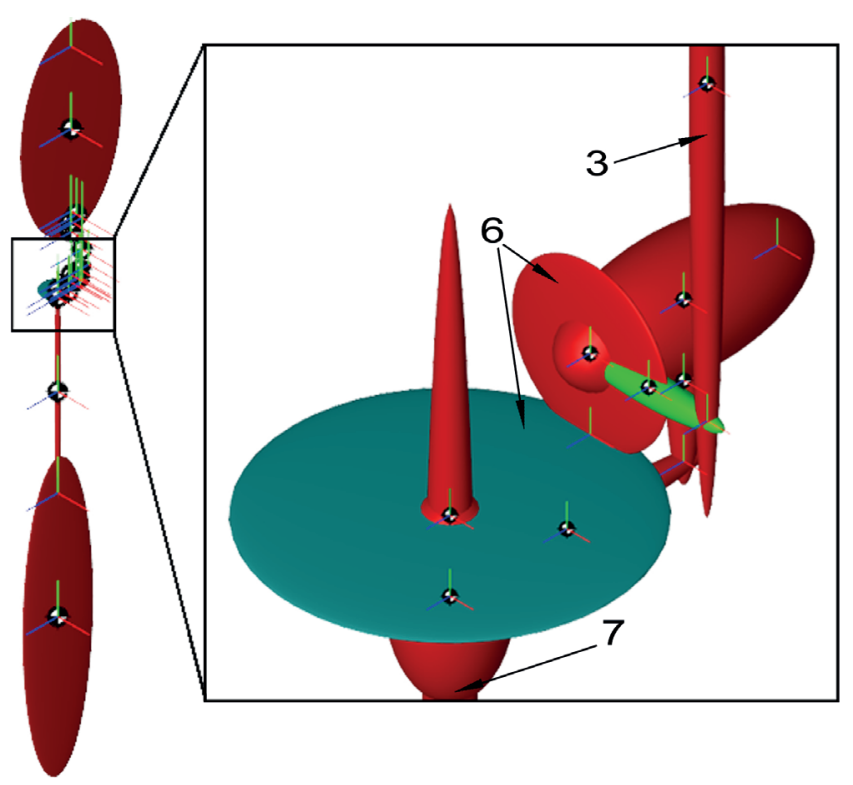

Fig. 6. Elements of wind-steering system kinematics visualized in Matlab software with the use of SimMechanics library; for notation - see Fig.2.

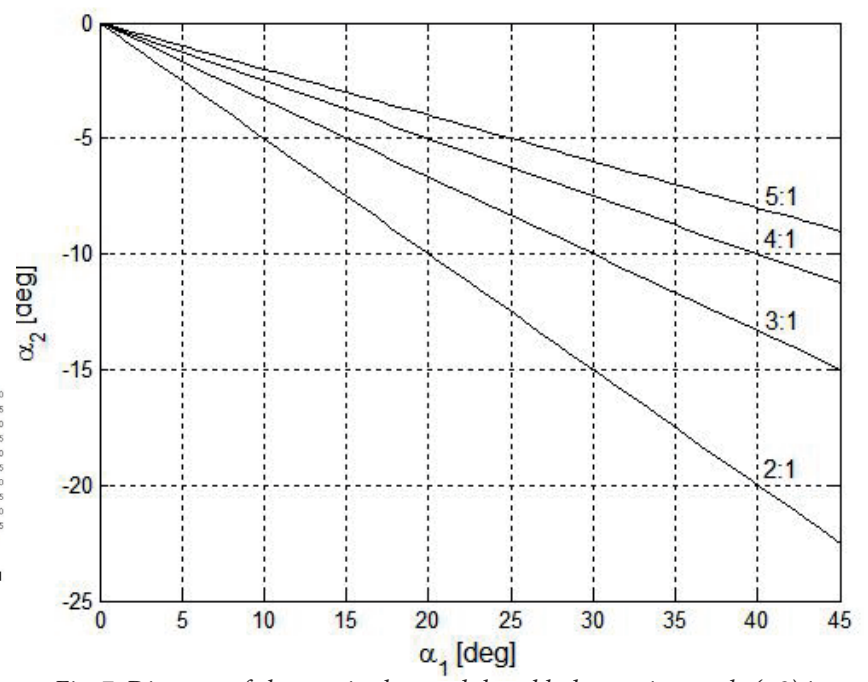

Fig. 7. Diagram of changes in the pendulum blade rotation angle $(\alpha 2)$ in function of the windvane inclination angle ( $\alpha 1)$, for various values of the bevel gear ratio

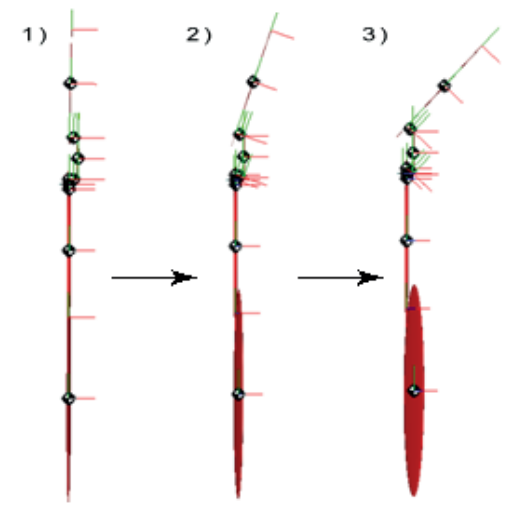

Fig. 8. Visualization of the mathematical model at set changes in position of the windvane. 1 - equilibrium position, 2 - intermediate position, 3- maximum inclination limited by constructional conditions

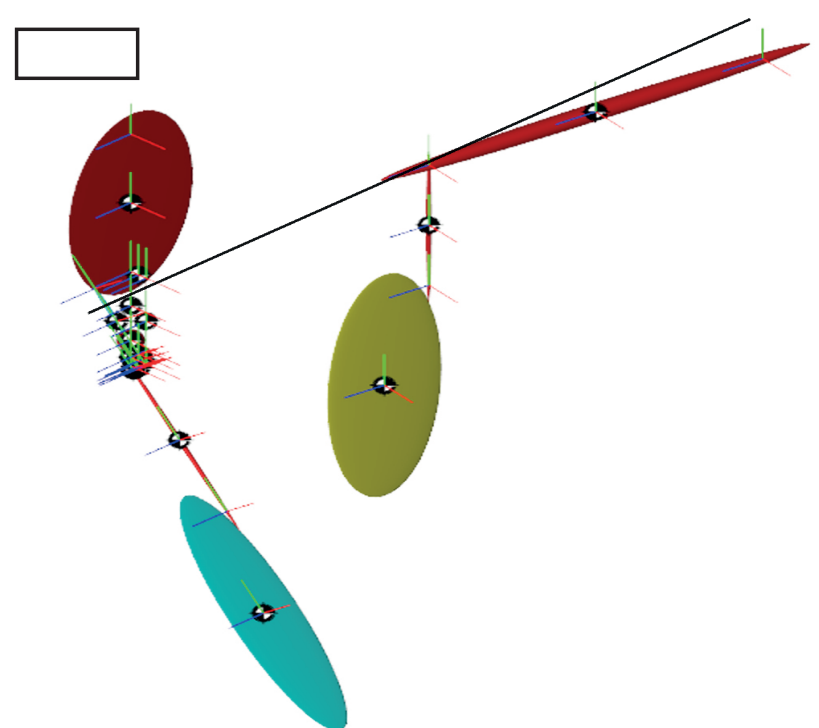

Fig. 9. Visualization of the mathematical model at inclination of the pendulum which generates inclination of the main rudder

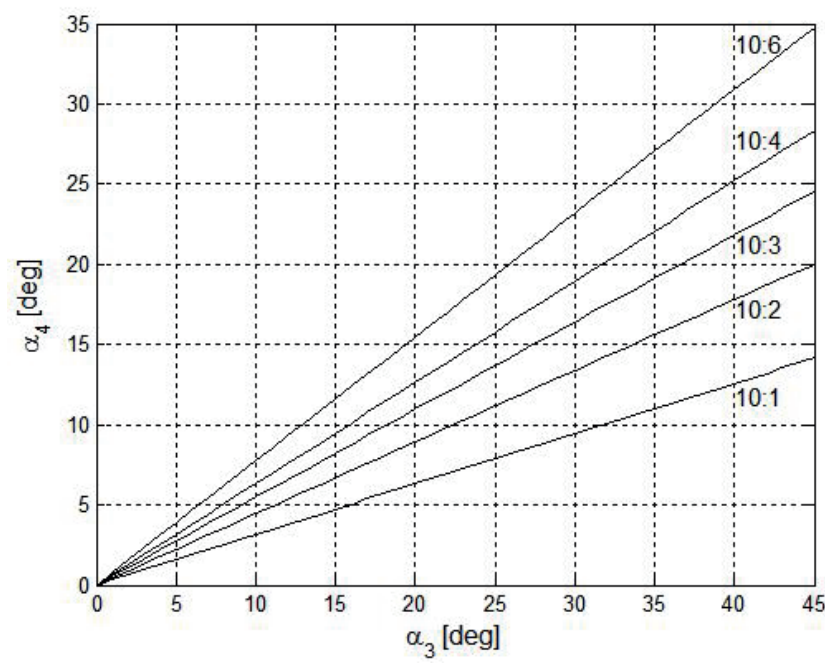

Fig. 10. Diagram of changes in the main rudder rotation angle $(\alpha 4)$ in function of the pendulum inclination angle $(\alpha 3)$ for various values of the ratio of the tiller length (L11) and wind-steering system arm (L4)

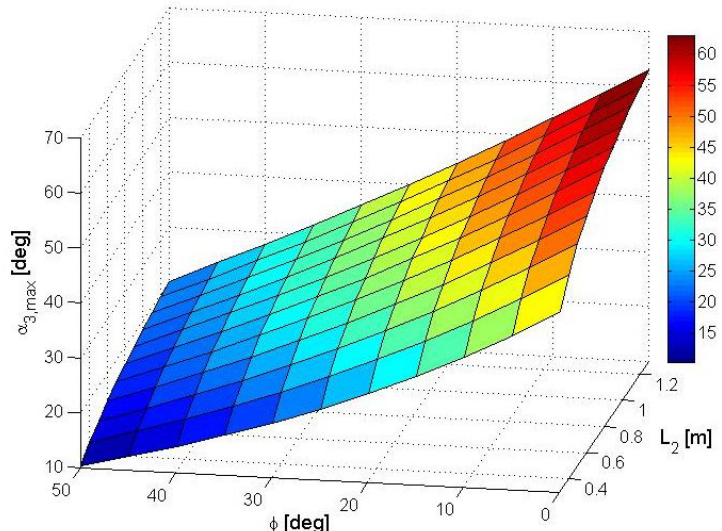

Fig. 11. Diagram of the maximum inclination of the pendulum ( $\alpha 3$ max) in function of yacht's heel angle and the blade length (L8); under assumption on the constant length of the pendulum post $L 7=0,6 \mathrm{~m}$ and the length of wetted part of the pendulum blade, equal to $20 \%$ L8 


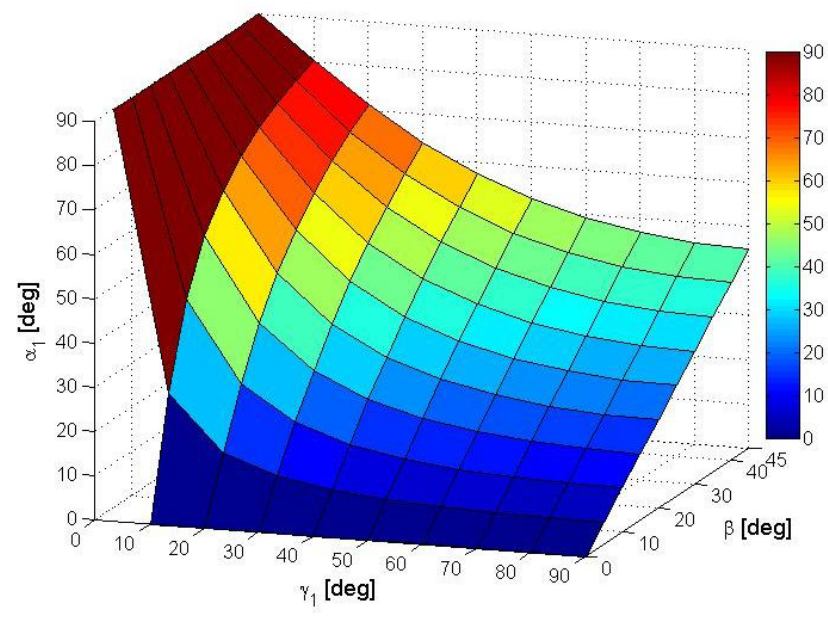

Fig. 12. The windvane inclination angle $(\alpha 1)$ in function of the windvane jamming angle $(\gamma 1)$ and the angle of yacht's departure from course, $(\beta)$

Analysing the diagram of Fig. 11 one can state that, under assumption on the permissible value of sailing yacht's heel angle not exceeding $30^{\circ}$, the pendulum inclination amplitude should be contained in the range of $30^{\circ} \div 40^{\circ}$ (depending on a value of applied blade length) in order to ensure possible operation of the considered system in given conditions. The limitation of the maximum inclination angle can be obtained most easily by constraining windvane inclination. It may be reached with the use of a constructional limiter (stopper) or by adjustment of the windvane jamming angle $(\gamma)$.

Under assumption that the maximum permissible yacht's departure from its course amounts to $\beta=30^{\circ}$, the windvane jamming angle equal to about $20^{\circ}$ would be able to prevent the system against sudden loss of stability due to drop of the steering moment (owing to pendulum emerging off the water) in heavy sailing conditions (Fig. 11). On the other hand, greater values of the angle $\gamma$ are deemed unfavourable because they would generate too low values of the angle $\alpha_{1}$ at typical yacht departures from course, ranging $\pm 10^{\circ}$.

Maximum windvane inclination angle implies a range of applicable values of bevel gear ratio. Maximum value of lateral hydrodynamic force is reached, depending on an applied blade profile and Reynolds number determining kind of flow, for values of angle of attack equal to about $10^{\circ}$ [9]. The above discussed conditions show that in the case in question it is possible to apply $\mathrm{R}_{6.1} / \mathrm{R}_{6.2}$ ratio $<4 / 1$ (Fig. 7). It makes it possible to obtain an appropriately large value of the moment capable of rotating the pendulum blade. As results from elementary sailing theory, at increasing heel of yacht its ardency (i.e. its tendency to automatic departure from course toward wind's eye) grows [1]. In the conditions of $30^{\circ}$ heel angle it is necessary, at least for some yachts, to make main rudder inclination greater than $20^{\circ}$ in order to keep the yacht on its course [1]. Therefore the wind-steering system should cope with such inclinations. It is implied by the condition: $\mathrm{L}_{11} / \mathrm{L}_{4}<10 / 3$ for the ratio between the length of main rudder tiller and length of arm of wind-steering system.

\section{Conclusions}

In designing the wind-steering systems for various types of yachts intended for the operating in extremely different weather conditions the crucial issue is to properly select geometrical parameters of such device. Choice of control characteristics may be preliminarly made on the basis of model calculations by using only basic data available from the builder or owner of the considered yacht. It diminishes time and cost of performing such adaptation.

It has been proved that the proposed mathematical model of the wind-steering system with single-stage servopendulum correctly reproduces performance of the actual system as far as its kinematics is concerned. After taking into account external excitations and friction in kinematic pairs the extended model may be used for fast prototyping the devices of the kind.

Moreover, in this work the main geometrical parameters of the system were preliminarly determined on the basis of analysis of construction of wind-steering systems and geometrical constraints imposed on them. It was shown that optimum values of control settings are contained within the following ranges:

- for the windvane jamming angle: about $20^{\circ}$; alternatively, in order to reach a greater amplification, the angle may be regulated within the range of $5^{\circ} \div 15^{\circ}$ accompanied with application of a constructional stopper to limit maximum inclination angle to $40^{\circ}$;

- $\quad$ for the bevel gear ratio: $3 / 1 \div 4 / 1$;

- for the ratio between the length of main rudder tiller and the length of wind-stering system arm: $10 / 3 \div 10 / 2$ that ensures to transfer a properly large moment at maintaining a demanded range of rotation for main rudder.

\section{Bibliography}

1. Anderson B. D.: The Physics of Sailing Explained. Adlard Coles Nautical, London, 2003

2. Dąbrowski Z., Skórski W. W.: Assesment of operational correctness of wind-steering system (in Polish). Przegląd Mechaniczny, No. $5 \div 6 / 1996$, pp. $3 \div 4$

3. Dąbrowski Z., Skórski W. W.: Wind-steering system with double servo-mechanism ( in Polish). Przegląd Mechaniczny, No.5/2001, pp. $3 \div 4$

4. Dąbrowski Z., Skórski W. W.: Introduction to theory of wind-steering systems ( in Polish). Wydawnictwo ITEPIB ( Publishers), Warszawa-Radom, 2005

5. Forthman P. Ch.: Self-steering under sail. Autopilots and Wind-steering Systems. Mcgraw-Hill, London, 1998

6. Górecki P., Stankiwicz B., Szajkowski P.: Design of a windsteering system with the active setting of windvane jamming angle (in Polish). Przegląd Mechaniczny, No. 9/2004, pp. $23 \div 26$ 
7. Jaskulski A.: Autodesk Inventor Professional 2014PL /2014+. Fusion/Fusion 360. Design methodology (in Polish). Wydawnictwo Naukowe PWN ( Publishers), Warszawa, 2013

8. Marchaj C.: Sail Performance Theory and Practice. Adlard Coles Nautical, London, 1996

9. Marchaj C.: Seaworthiness; the forgotten factor (in Polish). Almapress, Warsaw, 2002

10. Osowski S.: Modelling of dynamic systems by using Simulink language ( in Polish). Oficyna Wyd. Pol. Warsz. ( Publishing House of Warsaw Univ. of Techn.), Warsaw, 1999

11. Tarnowski W., Bartkiewicz S.: Mathematical modelling and computer simulation of continuous dynamic processes (in Polish). Wydawnictwo Feniks ( Publishers), Koszalin, 1998

12. www.ariesvane.com. Aries Standard - Peter Matthiesen. Mollegade 54, Holm DK 6430 Nordborg, Denmark

13. www.selfsteer.com. Auto Helm. Scanmar International. 432 South 1st Street, Richmond CA, 94804-2107 USA

14. www.windpilot.com. Windpilot USA. Madeira Beach Fl ,33738-8565 USA

\section{CONTACT WITH AUTHOR}

\author{
Andrzej Piętak \\ Maciej Mikulski \\ Marek Melzacki \\ Kamil Czerwiński
}

University of Warmia and Mazuria in Olsztyn

Faculty of Technical Sciences

Chair of Mechatronics

46 A, Słoneczna St.

10-710 Olsztyn,

POLAND

Tel.: +48 895245100

e-mail: maciej.mikulski@uwm.edu.pl 